\title{
Determination of Terpenoid Content in Pine by Organic Solvent Extraction and Fast-GC Analysis
}

\author{
Anne E. Harman-Ware ${ }^{1 *}$, Robert Sykes ${ }^{1}$, Gary F. Peter ${ }^{2}$ and Mark Davis ${ }^{1}$ \\ ${ }^{1}$ National Bioenergy Center, National Renewable Energy Laboratory, Golden, CO, USA, ${ }^{2}$ School of Forest Resources and \\ Conservation, University of Florida, Gainesville, FL, USA
}

Terpenoids, naturally occurring compounds derived from isoprene units present in pine oleoresin, are a valuable source of chemicals used in solvents, fragrances, flavors, and have shown potential use as a biofuel. This paper describes a method to extract and analyze the terpenoids present in loblolly pine saplings and pine lighter wood. Various extraction solvents were tested over different times and temperatures. Samples were analyzed by pyrolysis-molecular beam mass spectrometry before and after extractions to monitor the extraction efficiency. The pyrolysis studies indicated that the optimal extraction method used a 1:1 hexane/acetone solvent system at $22^{\circ} \mathrm{C}$ for $1 \mathrm{~h}$. Extracts

OPEN ACCESS

Edited by:

Subba Rao Chaganti, University of Windsor, Canada

Reviewed by: Yu-Shen Cheng, National Yunlin University of Science and Technology, Taiwan Yunqiao $\mathrm{Pu}$

Georgia Institute of Technology, USA

${ }^{*}$ Correspondence: Anne E. Harman-Ware anne.ware@nrel.gov

Specialty section: This article was submitted to Bioenergy and Biofuels, a section of the journal Frontiers in Energy Research

Received: 21 October 2015 Accepted: 08 January 2016

Published: 25 January 2016

Citation: Harman-Ware AE, Sykes R, Peter GF and Davis M (2016) Determination of Terpenoid Content in Pine by Organic

Solvent Extraction and Fast-GC

Analysis.

Front. Energy Res. 4:2. doi: 10.3389/fenrg.2016.00002 from the hexane/acetone experiments were analyzed using a low thermal mass modular accelerated column heater for fast-GC/FID analysis. The most abundant terpenoids from the pine samples were quantified, using standard curves, and included the monoterpenes, $\alpha$ - and $\beta$-pinene, camphene, and $\delta$-carene. Sesquiterpenes analyzed included caryophyllene, humulene, and $\alpha$-bisabolene. Diterpenoid resin acids were quantified in derivatized extractions, including pimaric, isopimaric, levopimaric, palustric, dehydroabietic, abietic, and neoabietic acids.

Keywords: fast-GC, pyrolysis-molecular beam mass spectrometry, cell wall chemistry, renewable materials, biofuels, bioproducts, biomaterials

\section{INTRODUCTION}

Renewable chemicals, including fuels, solvents, fragrances, flavors, and pharmaceutical compounds, can be generated or extracted from renewable biomass sources. Many types of compounds can be generated from different components of the biomass, e.g., ethanol from the carbohydrate fraction or biodiesel from the lipid components in biomass. Other biomass components, including lignin and oleoresin excretions from conifers, have also been used as a source of renewable chemicals. For example, pine oleoresin is used to generate turpentine, a solvent and source of synthetic platform chemicals such as $\alpha$-pinene (Palmer, 1943; Beglinger, 1958). Terpenoids, naturally occurring organic compounds derived from isoprene units, are the primary constituents of pine oleoresin (Palmer, 1943; Bohlmann and Keeling, 2008; Rodrigues-Corrêa et al., 2012). Monoterpenes $\left(\mathrm{C}_{10}\right)$, sesquiterpenes $\left(\mathrm{C}_{15}\right)$, and diterpenoid resin acids $\left(\mathrm{C}_{20}\right)$, the main terpenoids found in pine oleoresin, are a

Abbreviations: BSTFA, N,O-Bis(trimethylsilyl)trifluoroacetamide; GC/FID, gas chromatography/flame ionization detector; LTM MACH, low thermal mass modular accelerated column heater; PLW, pine lighter wood; PS, pine sapling; py-MBMS, pyrolysis-molecular beam mass spectrometry. 
valuable source of chemicals with many industrial applications (Beglinger, 1958; Martin et al., 2002; Monteiro and Veloso, 2004; Bohlmann and Keeling, 2008; Harvey et al., 2009; RodriguesCorrêa et al., 2012). Turpentine is composed of monoterpenes and is used in the flavor and fragrance industry (Bohlmann and Keeling, 2008; Rodrigues-Corrêa et al., 2012). Other uses for terpenoid compounds have been found in pharmaceutical, cosmetics, and polymer industries (Beglinger, 1958; Bohlmann and Keeling, 2008; Rodrigues-Corrêa et al., 2012). Monoterpenes and sesquiterpenes have also been investigated as potential sources of renewable fuel (Monteiro and Veloso, 2004; Harvey et al., 2009; Peralta-Yahya et al., 2011; Renninger et al., 2011; Meylemans et al., 2012; Rodrigues-Corrêa et al., 2012; Hellier et al., 2013; Vallinayagam et al., 2014).

Efforts have been made to understand the genetic, ecological, and physicochemical processes behind the production and accumulation of terpenoids in pine and other feedstocks (Nerg et al., 1994; Manninen et al., 2002; Martin et al., 2002; Bojovic et al., 2005; Schmidt et al., 2011; Achotegui-Castells et al., 2013; Susaeta et al., 2014). For this type of research, it is important to accurately measure the terpenoid content in biomass to be able to compare the variables potentially affecting terpenoid production and accumulation. With the wide variety of uses and applications of terpenoid components as well as the biological variability associated with their formation, development of rapid analytical methods used to characterize terpenoids and measure their abundance in the biomass is becoming increasingly important.

Currently, analytical methods primarily use hexane or other non-polar solvents to extract terpenoid components from pine and other biomass sources and GC/MS to identify and quantify the components of the extract (Lewinsohn et al., 1993; Manninen et al., 2002; Bojovic et al., 2005; Thompson et al., 2006; Varming et al., 2006; Ormeño et al., 2007, 2010; Zhao et al., 2010; AchoteguiCastells et al., 2013). There have been other methods and solvents used to extract and quantify terpenoids in biomass, including accelerated solvent extraction, dynamic headspace analysis as well as the use of methyl tert-butyl ether and derivatization agents during extraction (Martin et al., 2002; Varming et al., 2006; Fojtová et al., 2008; Zhao et al., 2010). Several terpenoids are available to be used as standards for quantitation, whereas the abundance of others are estimated based on assumption of response factors relative to internal standards (Martin et al., 2002; Varming et al., 2006; Ormeño et al., 2007, 2010; Fojtová et al., 2008; Zhao et al., 2010; Achotegui-Castells et al., 2013). However, the more polar resin acids, such as abietic, dehydroabietic, neoabietic, palustric, pimaric, and isopimaric acid, are not accounted for in their entirety from hexane (or other non-polar) extractions, especially without derivatization prior to GC analysis, and constitute large fractions of pine oleoresin (Martin et al., 2002; Keeling and Bohlmann, 2006). Accelerated solvent extractions require the use of high temperatures and pressures and reported methyl tertbutyl ether extractions are tedious and time consuming (Martin et al., 2002; Fojtová et al., 2008). Additionally, most methods require multiple types or steps of extractions to remove different types of terpenoids or utilize equipment, such as shaker tables and Soxhlet extractors. Currently, there is not a high-throughput technique that successfully extracts and accurately measures both the polar and non-polar most abundant terpenoid contents in pine or other biomass samples.

The goal of this investigation was to develop a rapid, accurate, screening method using an optimized solvent system to quantify the abundant terpenoids in pine biomass. This technique can be used to compare biomass genetic transformations, biological variation, and the effects of physical and chemical treatments on plants in order to screen for desired genetic constructs and treatments. The method minimizes the use of specialized equipment such as a Soxhlet apparatus or shaker table and does not require multiple extraction steps or labor-intensive treatment of the biomass, such as grinding. Implementation of this method allows rapid screening of pine samples based on terpenoid content; which directly affects the potential of the pine to be used as a source of renewable fuels and chemicals.

We evaluated the effects of the solvent type, time, and temperature used in the extractions. In an effort to develop a more rapid method, a low thermal mass modular accelerated column heater (LTM MACH) GC/FID, also known as ballistic or fast-GC, was used to analyze the extracted components using a 3.5 min GC method. Fast-GC is a method that has been used to successfully and rapidly analyze many types of samples, including petroleum products, natural oils, and plant extracts (Luan and Szelewski, 2008; Firor, 2011). Pyrolysis-molecular beam mass spectrometry (py-MBMS), a technique used to study biomass components based on their pyrolyzate profiles,(Evans and Milne, 1987; Sykes et al., 2009) was also used to supplement the analysis of the terpenoid components of the pine samples before and after extractions in order to quantify extraction efficiency.

\section{MATERIALS AND METHODS}

\section{Preparation of Calibration Standards}

Terpenoid calibration standards were obtained from Sigma Aldrich, Alfa Aesar, CanSyn Chem. Corp., and purified bisabolene was provided by the Joint BioEnergy Institute, Emeryville, CA, USA. Calibration standards $(5-400 \mu \mathrm{g} / \mathrm{mL})$ were prepared in hexane/acetone (v/v, 1:1) and hexadecane was used as an internal standard (1 mg/mL in hexane/acetone (1:1) stock solution). Figure 1 shows the terpenoid compounds that were calibrated in this method. Trimethylsilyl derivatives of resin acids (pimaric, levopimaric, isopimaric acid, neoabietic acid, abietic acid, palustric acid, dehydroabietic acid) were prepared by making serial dilutions of the resin acids in hexane/acetone (1:1) and derivatizing each standard individually using N,O-Bis(trimethylsilyl) trifluoroacetamide (BSTFA) reagent purchased from Sigma Aldrich. Stearic and palmitic acids were also calibrated for on the GC and derivatized using BSTFA. Calibration standards were prepared by adding $500 \mu \mathrm{L}$ of each calibration stock to a GC vial with $100 \mu \mathrm{L}$ of internal standard stock solution and $100 \mu \mathrm{L}$ BSTFA reagent (BSTFA for diterpenoids only). The mixture was briefly purged with nitrogen and heated to $75^{\circ} \mathrm{C}$ for $1 \mathrm{~h}$ prior to analysis by GC/FID. To validate the calibrations, $1 \mathrm{mg}$ of four different samples of slash pine oleoresin were dissolved in $2 \mathrm{~mL}$ of the hexane/acetone solvent. Fast-GC analysis was performed 


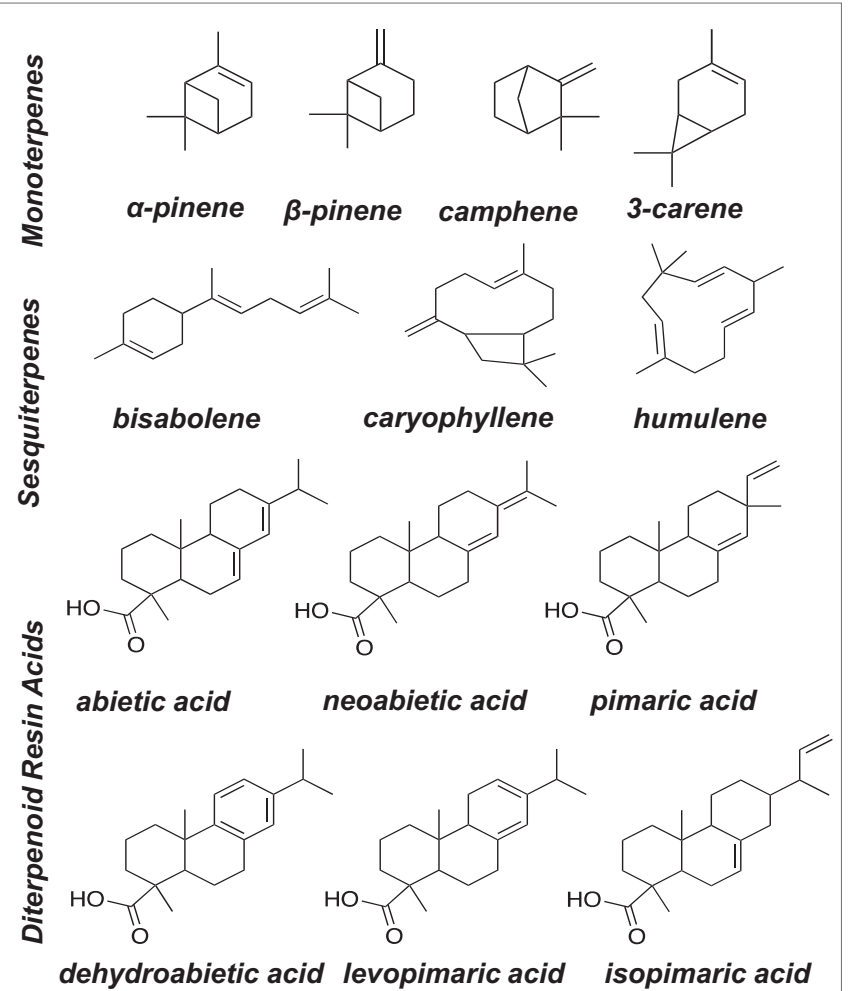

FIGURE 1 | Mono-, sesqui-, and diterpenoids analyzed in ground pine lighter wood and pine sapling cross section extraction solvents for high-throughput extraction and fast-GC/FID analysis.

on each oleoresin sample using a $500 \mu \mathrm{L}$ underivatized aliquot with $50 \mu \mathrm{L}$ of hexadecane internal standard stock solution and a $500 \mu \mathrm{L}$ aliquot that was derivatized by adding to $50 \mu \mathrm{L}$ internal standard, and $100 \mu \mathrm{L}$ BSTFA reagent with brief nitrogen purging and heating to $75^{\circ} \mathrm{C}$ for $1 \mathrm{~h}$ prior to analysis by GC/FID. Trace terpenoids for which standards do not exist were not included in the calibration. However, they could be included when standards become available.

\section{Gas Chromotography}

An Agilent 6890 GC/FID was used to analyze the terpenoid calibration standards, derivatized pine resin, and the extracted samples from pine lighter wood (PLW) and loblolly pine sapling samples. The GC was equipped with an Agilent $10 \mathrm{~m} \times 0.10 \mathrm{~mm} \times 0.10 \mu \mathrm{m}$ DB-5 column LTM module used in a Gerstel MACH unit. The LTM column was connected to the inlet and the detector by $0.5 \mathrm{~m}$ of $0.10 \mathrm{~mm}$ fused silica deactivated transfer lines. The inlet was run in splitless mode at $250^{\circ} \mathrm{C}$ and the column flow was $0.6 \mathrm{~mL} / \mathrm{min}$. The $\mathrm{GC}$ oven was isothermal at $250^{\circ} \mathrm{C}$ and the detector temperature was $250^{\circ} \mathrm{C}$. The LTM oven program began at $60^{\circ} \mathrm{C}$ for $0.75 \mathrm{~min}$ and was ramped to $325^{\circ} \mathrm{C}$ at a rate of $150^{\circ} \mathrm{C} / \mathrm{min}$ and held at the final temperature for $1 \mathrm{~min}$ for a total run time of approximately $3.5 \mathrm{~min}$. The rapid nature of this method does not differentiate isomers, for example $(+)$ and (-) $\alpha$-pinene, and developed for screening large sample sets of pine for total terpenoid content.

\section{Extraction of Terpenoids from Pine Lighter Wood}

Pine lighter wood was used to optimize extraction conditions because of its high terpenoid content. PLW samples were air dried to $5 \mathrm{wt} \%$ water and Wiley milled to 20 mesh particle size. Four extraction solvent systems were tested to determine the solvent that yielded the maximum amount of terpenes extracted from the PLW: hexane $(\mathrm{H})$, hexane:acetone (v/v, 1:1), hexane:diethyl ether (v/v, 1:1), and hexane:ethyl acetate (v/v, 1:1). Approximately $10 \mathrm{mg}$ of ground PLW was added to a $4 \mathrm{~mL}$ borosilicate glass vial and $2 \mathrm{~mL}$ of extraction solvent. Vials were then stored at temperatures of either $-22,2$, or $22^{\circ} \mathrm{C}$ for times of either 0.25 , 1,5 , or $24 \mathrm{~h}$ to evaluate the influence of time and temperature on each solvent extraction system. The solvent was transferred to another vial using a pipette and the biomass was dried in a vacuum oven at $40^{\circ} \mathrm{C}$ overnight. Next, $4 \mathrm{mg}$ of the dried biomass was added to Frontier pyrolyzer cups with Type A/D glass fiber filters for py-MBMS analysis. Unextracted PLW samples were also prepared for py-MBMS analysis.

The extract solvent containing the terpenoid components was then aliquoted for separate analysis of mono-/sesquiterpenoids and resin acids. Mono- and sesquiterpenoids were analyzed by combining neat solvent extract with hexadecane internal standard and analyzed using the GC method described in the previous section. To analyze for resin acids, approximately $1 \mathrm{~mL}$ of the extract solvent was combined with $0.25 \mathrm{~mL}$ of $0.1 \mathrm{M}$ aqueous ammonium carbonate. The aqueous layer was removed with a pipette and the organic layer was then dried over $100 \mathrm{mg}$ of $3 \AA$ molecular sieves for $1 \mathrm{~h}$. Then, $400 \mu \mathrm{L}$ of the dried organic layer was added to a GC vial with $50 \mu \mathrm{L}$ of internal standard and $100 \mu \mathrm{L}$ of BSTFA, heated to $75^{\circ} \mathrm{C}$ for $1 \mathrm{~h}$ and analyzed by GC using the method described in herein. A flow chart of the extraction process and sample preparation is shown in Figure 2.

The extraction and derivatization method was validated for recovery of total terpenoids by a standard addition method. The extract solvent from ground PLW, as well as the extract solvent from freshly cut pine sapling cross sections, was spiked using diterpenoid standards. Terpenoids were extracted as described previously and the extract solvent was spiked with two concentrations of abietic acid and neoabietic acid ( $40-80 \mu \mathrm{g} / 400 \mu \mathrm{L}$ aliquot extract) prior to sample analysis. For these experiments, spiked extraction solvent was washed with ammonium carbonate, dried with molecular sieves, and added to a GC vial containing $100 \mu \mathrm{L}$ of internal standard stock solution and $100 \mu \mathrm{L}$ of BSTFA or Methyl-8 reagent (Thermo Scientific). For BSTFA, the vials were heated to $75^{\circ} \mathrm{C}$ for $1 \mathrm{~h}$; and for the Methyl- 8 derivatives, the vials were heated to $85^{\circ} \mathrm{C}$ for $30 \mathrm{~min}$ prior to fast-GC analysis. Standards were also derivatized with Methyl-8 for calibration to test derivatization efficiency.

\section{Extraction Efficiency Evaluation by Pyrolysis-Molecular Beam Mass Spectrometry}

Pine samples before and after extractions were pyrolyzed using a Frontier PY-2020 iD autosampler pyrolysis unit and pyrolysis vapors were analyzed with an Extrel Model Max1000 MBMS. (Sykes et al., 2009) Pyrolysis was conducted under a He flow 




FIGURE 2 | Terpenoid extraction flow chart.

rate of $0.9 \mathrm{~L} / \mathrm{min}(\mathrm{STP})$ and furnace temperature of $500^{\circ} \mathrm{C}$ for a $1.5 \mathrm{~min}$ acquisition time per sample, although pyrolysis was complete in $<30 \mathrm{~s}$. The interface and transfer lines were maintained at $350^{\circ} \mathrm{C}$. Calibration standards for py-MBMS reference spectra of terpenoids were prepared in acetone. Abietic acid was used as a reference for diterpenoids $(m / z=302,285,239)$, caryophyllene was used to reference sesquiterpenoids $(m / z=204)$, and $\alpha$-pinene was used to reference monoterpenes $(m / z=93)$. Solutions of each terpenoid ( $40 \mu \mathrm{L}$ of $5 \mathrm{mg} / \mathrm{mL}$ ) were added to empty pyrolyzer cups containing glass fiber filter disks. The solvent was allowed to evaporate prior to py-MBMS analysis.

\section{Extraction of Terpenoids from Pine Saplings}

Greenhouse-grown loblolly pine saplings (16-month-old) were obtained from ArborGen and grown in a greenhouse at the National Renewable Energy Laboratory prior to sampling. The plants were trimmed $1 \mathrm{~cm}$ above the soil and five cross sections, each $2^{\prime \prime}$ apart, were taken from the tree, while the bark was removed immediately prior to taking each cross section sample. Each cross section sample, approximately $50 \mathrm{mg}$ dry weight (100 mg wet weight), was immediately added to a vial containing $2 \mathrm{~mL}$ of hexane/acetone and stored at room temperature for $1 \mathrm{~h}$ prior to sample analysis by fast-GC/FID. After the biomass was extracted, it was dried in a vacuum oven at $40^{\circ} \mathrm{C}$ overnight and then $4 \mathrm{mg}$ of the dried biomass was added to $80 \mu \mathrm{l}$ pyrolyzer cups with glass fiber filters for py-MBMS analysis. Unextracted cross section samples were also prepared for py-MBMS analysis.

\section{RESULTS}

\section{Extraction Optimization and py-MBMS Analysis}

Pine lighter wood was chosen as a feedstock to optimize the extraction conditions, since it is known to have high oleoresin content (Beglinger, 1958). Py-MBMS of the PLW before and after the extractions was used to quantify the extraction efficiency of terpenoid removal. The intensity of the ions corresponding to the presence of terpenoids in unextracted PLW was considered the starting amount of terpenoids (100\%) present in the samples. Figure 3A shows the comparison of intensities of the diterpenoid-based ion, $m / z=302$, before and after extractions where the PLW sample was in solvent for $1 \mathrm{~h}$ at $22^{\circ} \mathrm{C}$ (room temperature) using the four different solvent systems. The percent values reported for each extraction solvent correspond to the percentage intensity of each ion lost from the unextracted material, reflecting the approximate extraction efficiency. Ions corresponding to the presence of mono- and sesquiterpenoids were also monitored, but their presence and intensity can also result from the fragmentation of the diterpenoids present in the samples. Hence, these ions were only semi-quantitative and were not used for comparison. Py-MBMS results indicated that the solvent systems that incorporated the polar solvents extracted more terpenoids than the hexane-only extractions. It was also found that the extractions performed at colder temperatures and over longer periods of time (beyond $1 \mathrm{~h}$ ) did not influence the amount of terpenoids extracted. Error bars in Figure 3A are SD for triplicate extractions. Figure $\mathbf{3 B}$ shows that the extraction is also efficient for sapling cross section samples. (The data shown in Figure 3B correspond to the extraction from a single sapling's cross sections; hence, there are no replicates or error bars, which incorporates the biological variability, but not the variability associated with the method). Therefore, the optimal extraction conditions were determined to be the hexane/acetone solvent system for $1 \mathrm{~h}$ at $22^{\circ} \mathrm{C}$. Additional research to determine the variability of terpenoids within a tree and across trees is currently under way, but was not the focus of this method development work.

The amount of PLW used to determine the terpenoid content (approximately $10 \mathrm{mg}$ in $2 \mathrm{~mL}$ solvent) was chosen as 


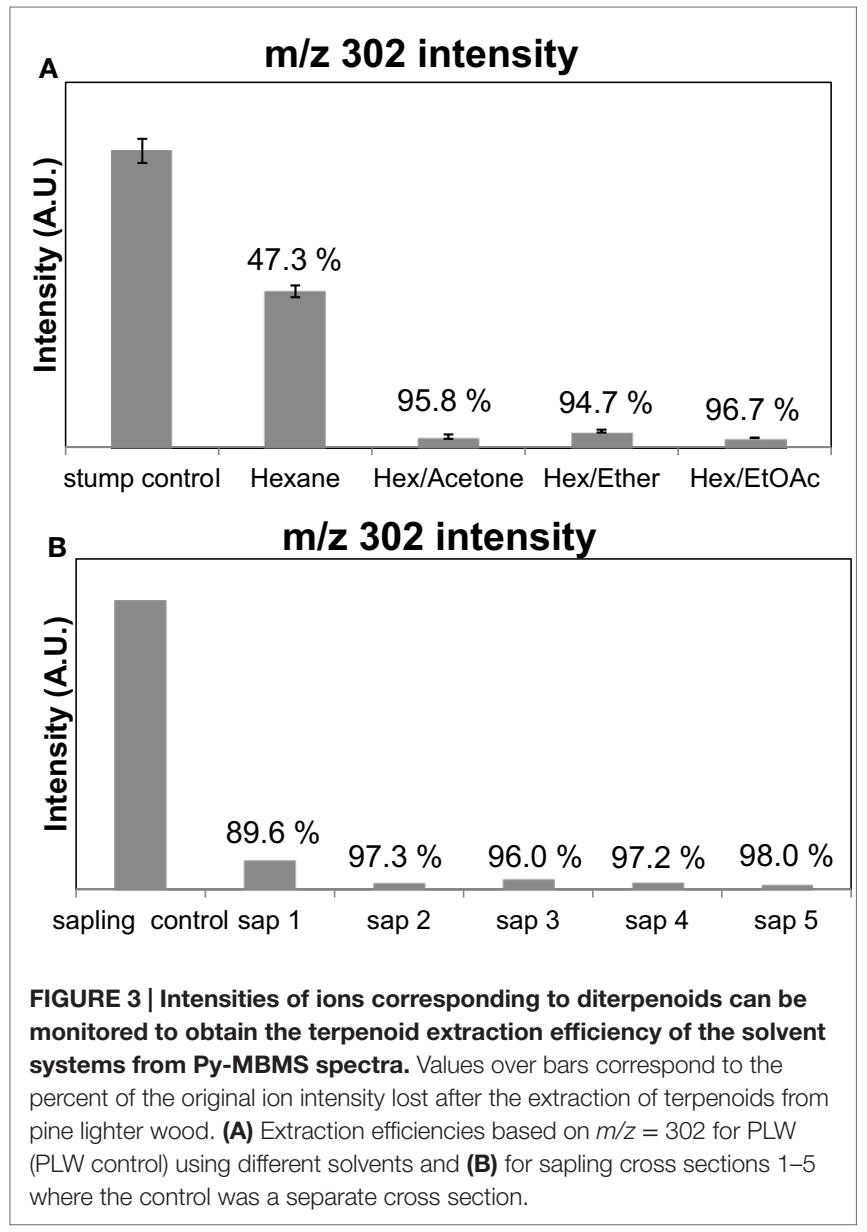

the concentration of the analytes detected from this amount of sample was within the dynamic range of the calibrations for each analyte. Fresh pine cross section or core samples containing high moisture and lower terpenoid content need to be used in larger quantities, ranging from 20 to $150 \mathrm{mg}$ of dry weight material for $2 \mathrm{~mL}$ of extract solvent. While each terpenoid analyte has its own detection limit, the limit of quantification can vary from detector to detector, this method allows for determination of most analytes as low as 0.01 dry wt $\%$ of the biomass and some analytes as low as 0.002 dry wt\%. The speed of preparation of the samples can vary by individual, but combined with the GC analysis of $3.5 \mathrm{~min}$, the extraction and total terpenoid analysis of 200 separate pine samples per week (800 injections total, counting duplicates) are possible using this extraction technique. By contrast, typical GC methods are on the order of 20-40 min, making the GC analysis of this method approximately 10 times faster, not counting the increased cooling speed between injections of the LTM MACH.

\section{Validation of Derivatization of the Terpenoid Extracts for GC Analysis}

Table 1 shows the terpenoid content determined in PLW and PS from fast-GC analysis using the hexane/acetone solvent system for $1 \mathrm{~h}$ at $22^{\circ} \mathrm{C}$ using BSTFA as a derivatizing reagent. The BSTFA was chosen as the optimal derivatizing agent based on the ability to recover known amount of resin acid spiked in extract solvent (where the concentration of resin acids in the extract was previously determined based on external calibrations). Extraction solvent from fresh-cut PS and extraction solvent from ground PLW were spiked with abietic and neoabietic acid to test for the recovery of these resin acids using the selected extraction method. The $1 \mathrm{~h}$ room temperature hexane/acetone extraction solvents from PLW samples and PS samples were prepared according to the procedure described in the experimental section and analyzed for total terpenoid content. The extraction solvent was also aliquoted and spiked with abietic and neoabietic acid prior to sample analysis (ammonium carbonate washing and molecular sieve drying) and analyzed for terpene content using the two different derivatizing agents. Table 2 shows the recovery of the total resin acids from the pine sapling cross section samples. The results suggest that the Methyl-8 reagent is not a favorable derivatizing reagent due to its inability to recover all of the resin acids known to be present in the extraction solvent from the fresh-cut pine sapling samples. The Methyl- 8 is likely deactivated by the presence of any water or interfering metabolites that prevent methylation of the resin acids. Methyl- 8 was capable of recovering more of the resin acids from the lighter wood when not washing or drying the extract solvent, indicating that the fresh samples may contain water or other metabolites that inhibit the methylation of the resin acids. In addition to inefficient derivatization of the resin acids, the Methyl-8 reagent also showed high standard deviations from replicated experiments using the same extract solvent from a particular pine sample.

The majority of terpenoids extracted from pine samples can be successfully resolved using a 3.5 min ballistic GC method as shown in the chromatograms in Figure 4. Monoterpenes that were monitored included $\alpha$ - and $\beta$ - pinene, carene, and camphene. Sesquiterpenes that were accounted for included humulene, caryophyllene, and bisabolene. Diterpenoid resin acids that were quantified based on the presence of their trimethylsilyl derivatives included pimaric, levopimaric, isopimaric, palustric, dehydroabietic, abietic, and neoabietic acids. This method was unable to resolve isopimaric from palustric acid and levopimaric from dehydroabietic acid so the response from these compounds was averaged for their content determination. Other terpenoid compounds can also be calibrated and accounted for using this method as long as standards are available. While other terpenoids may be present in conifer or pine oleoresin that are unaccounted for using limited calibrated standards or could be co-eluting (particularly the diterpenoids), the total terpenoid content determination may still be accurately reflected using representative standards and responses for each compound, as demonstrated in the spiking experiment (results in Table 2) and additionally discussed below.

To validate the calibration and wt $\%$ recovery of the terpenoid components based on this analysis procedure, $1 \mathrm{mg}$ of four resin samples secreted from slash pine were extracted in $2 \mathrm{~mL}$ of hexane/acetone using the same derivatization method as the calibration standards and the pine extract solvents. The fast-GC analysis of the resins, assumed to be almost entirely terpenoid components, accounted for an average of $97 \%( \pm 6 \%)$ of the mass of the resins based on the presence of the calibrated compounds. 
TABLE 1 | Terpenoid content (dry wt\%) of pine lighter wood (PLW) and pine sapling cross sections (PS).

\begin{tabular}{|c|c|c|c|c|c|c|c|c|}
\hline & $\alpha$-pinene & $\boldsymbol{\beta}$-pinene & Pimaric acid & $\begin{array}{l}\text { Isopimaric/ } \\
\text { palustric acid }\end{array}$ & $\begin{array}{l}\text { Dehydroabietic/ } \\
\text { levopimaric acid }\end{array}$ & Abietic acid & $\begin{array}{c}\text { Neoabietic } \\
\text { acid }\end{array}$ & Total \\
\hline \multicolumn{9}{|c|}{ PLW } \\
\hline & $0.26( \pm 0.08)$ & $0.03( \pm 0.03)$ & $0.95( \pm 0.11)$ & $2.09( \pm 0.08)$ & $2.48( \pm 0.11)$ & $13.38( \pm 0.70)$ & $2.39( \pm 0.17)$ & $21.57( \pm 0.91)$ \\
\hline \multicolumn{9}{|c|}{$\mathbf{P S}^{\mathrm{b}}$} \\
\hline 1 & $0.43( \pm 0.00)$ & $0.10( \pm 0.00)$ & $0.01( \pm 0.02)$ & $0.14( \pm 0.02)$ & $0.28( \pm 0.01)$ & $0.16( \pm 0.01)$ & $0.04( \pm 0.00)$ & $1.16( \pm 0.02)$ \\
\hline 2 & $0.69( \pm 0.00)$ & $0.17( \pm 0.00)$ & $0.00( \pm 0.00)$ & $0.03( \pm 0.01)$ & $0.02( \pm 0.01)$ & $0.10( \pm 0.00)$ & $0.17( \pm 0.02)$ & $1.18( \pm 0.02)$ \\
\hline 3 & $0.46( \pm 0.01)$ & $0.11( \pm 0.00)$ & $0.04( \pm 0.00)$ & $0.16( \pm 0.00)$ & $0.38( \pm 0.01)$ & $0.59( \pm 0.03)$ & $0.08( \pm 0.00)$ & $1.81( \pm 0.04)$ \\
\hline 4 & $0.57( \pm 0.00)$ & $0.14( \pm 0.00)$ & $0.03( \pm 0.00)$ & $0.13( \pm 0.01)$ & $0.28( \pm 0.01)$ & $0.25( \pm 0.01)$ & $0.05( \pm 0.00)$ & $1.46( \pm 0.02)$ \\
\hline 5 & $0.78( \pm 0.01)$ & $0.13( \pm 0.00)$ & $0.05( \pm 0.00)$ & $0.23( \pm 0.02)$ & $0.58( \pm 0.02)$ & $0.40( \pm 0.02)$ & $0.08( \pm 0.00)$ & $2.25( \pm 0.02)$ \\
\hline
\end{tabular}

${ }^{a}$ Averaged from analysis of three extractions.

${ }^{b}$ Averaged from duplicate GC analysis of each cross section extraction where 1 corresponds to the cross section at the bottom of the sapling and 5 is the top.

Dry $W t \%=100 \times$ (mass of terpenoid recovered in $2 \mathrm{~mL}$ )/(Mass dried, extracted biomass + mass of total terpenoids recovered).

TABLE 2 | Resin acid recoveries after spiking extract solvents from pine sapling cross sections and pine lighter wood.

\begin{tabular}{lcccc}
\hline $\begin{array}{l}\text { Spiking } \\
\text { experiment }\end{array}$ & $\begin{array}{c}\text { Sapling } \\
\text { extract (total } \\
\text { terpenoid } \\
\text { recovery) } \\
\text { BSTFA }\end{array}$ & $\begin{array}{c}\text { PLW extract } \\
\text { (total terpenoid } \\
\text { recovery) } \\
\text { BSTFA }\end{array}$ & $\begin{array}{c}\text { Sapling } \\
\text { extract (total } \\
\text { terpenoid } \\
\text { recovery) } \\
\text { Methyl-8 }\end{array}$ & $\begin{array}{c}\text { PLW extract } \\
\text { (total } \\
\text { terpenoid } \\
\text { recovery) } \\
\text { Methyl-8 }\end{array}$ \\
\hline $\begin{array}{l}\text { Abietic acid } \\
\text { level 1) }\end{array}$ & $86 \%( \pm 6 \%)$ & $95( \pm 2 \%)$ & $39 \%( \pm 28 \%)$ & $44 \%( \pm 27 \%)$ \\
$\begin{array}{l}\text { Abietic acid } \\
\text { (level 2) }\end{array}$ & $97 \%( \pm 12 \%)$ & $100( \pm 6 \%)$ & $18 \%( \pm 10 \%)$ & $37 \%( \pm 19 \%)$ \\
$\begin{array}{l}\text { Neoabietic } \\
\text { acid (level 1) }\end{array}$ & $94 \%( \pm 12 \%)$ & $94( \pm 6 \%)$ & $34 \%( \pm 6)$ & $60 \%( \pm 37 \%)$ \\
$\begin{array}{l}\text { Neoabietic } \\
\text { acid (level 2) }\end{array}$ & $90 \%( \pm 12 \%)$ & $100( \pm 5 \%)$ & $25 \%( \pm 6 \%)$ & $19 \%( \pm 6 \%)$ \\
\hline
\end{tabular}

Extract solvents from the samples were spiked, the solvents were worked-up according to the procedure and derivatized using two different reagents, BSTFA and Methyl-8. Level 1 is the $40 \mu \mathrm{g} / 400 \mu \mathrm{L}$ extract concentration spiking and level 2 is $80 \mu \mathrm{g} / 400 \mu \mathrm{L}$ extract concentration spiking.

Hence, the derivatization efficiency of the pine resin was similar to that of the standards and the solvent-extracted oleoresin from the pine samples can be accurately quantified relative to these standards.

\section{Terpenoid Content of Pine Lighter Wood}

As shown in Table 1, the PLW sample, having been ground and dried, contained very few volatile monoterpenes, primarily $\alpha$ - and $\beta$-pinene. Carene and camphene were not detected in the PLW extract solvent. No calibrated sesquiterpenes were identified in the PLW using this method. Trimethylsilyl diterpenoid resin acids (pimaric, levopimaric, isopimaric, palustric, dehydroabietic, abietic, and neoabietic acids) were detected in the PLW extract solvent. Several types of terpenoids detected in PLW in this study agree with reported terpenoids found in other pine sources (Nerg et al., 1994; Manninen et al., 2002; Bojovic et al., 2005; Ormeño et al., 2007; Bohlmann and Keeling, 2008; Rodrigues-Corrêa et al., 2012; Achotegui-Castells et al., 2013) and show some similarities with terpenoids present in spruce (Martin et al., 2002; Zhao et al., 2010). For example, the most abundant monoterpenes extracted from PLW were in agreement with the most abundant monoterpenes present in pine wood and foliage, being $\alpha$ - and $\beta$-pinene. Other monoterpenes and sesquiterpenes have been detected in the foliage of pine but may have not been present initially in the PLW or could have been lost during the drying of the PLW in this study.

Diterpenoids extracted from the PLW are representative of typical oleoresin secretions from conifer trees. The most abundant diterpenoids present in PLW included abietic acid ( $>13$ dry $\mathrm{wt} \%)$ and neoabietic acid (> 2 dry wt\%), with smaller quantities of isopimaric/palustric acid and dehydroabietic/levopimaric acid (being approximately 2 dry wt\%). These diterpenoids are also similar to those identified from spruce (Martin et al., 2002). PLW, the resinous portion of felled trees or stumps, is known to have higher oleoresin content than the wood, foliage, or bark from the live tree (Beglinger, 1958). The PLW in this study was shown to have total terpenoid content in excess of $20 \mathrm{wt} \%$ (dry basis) if referring to the maximum amount of terpenoids determined from the hexane/acetone extractions. The higher terpenoid composition from PLW in this study is consistent in comparison to the total terpenoid content, being $<5 \mathrm{wt} \%$, from the greenhousegrown loblolly saplings in this study and that reported for pine and spruce in the literature (Martin et al., 2002; Thompson et al., 2006; Ormeño et al., 2007; Zhao et al., 2010; Achotegui-Castells et al., 2013). The SD of the terpenoid content determined for the PLW as reported in Table 1 reflects the reproducibility of the method as each sample of PLW is considered to be homogeneous and should yield statistically similar results for each analysis.

\section{Terpenoid Content of Pine Sapling Cross Sections}

Chromatograms of the extract obtained from a greenhouse-grown loblolly pine sapling cross section (PS) are shown in Figure 4. Mono- and sesquiterpenoids elute before $2.1 \mathrm{~min}$, fatty acids elute around $2.5 \mathrm{~min}$, and trimethylsilyl derivatives of resin acids elute after $2.6 \mathrm{~min}$. PS samples were measured for total terpenoid content using the same procedure and GC analysis of the PLW. As shown in Figure 5 and Table 1, the PS had an overall lower terpenoid content, being $1-3 \mathrm{wt} \%$, than the PLW that had greater than $20 \mathrm{wt} \%$ terpenoids. The PS samples, extracted fresh, contained higher monoterpene content, being mostly $\alpha$-pinene and some $\beta$-pinene, than the PLW in each of the cross sections. No 


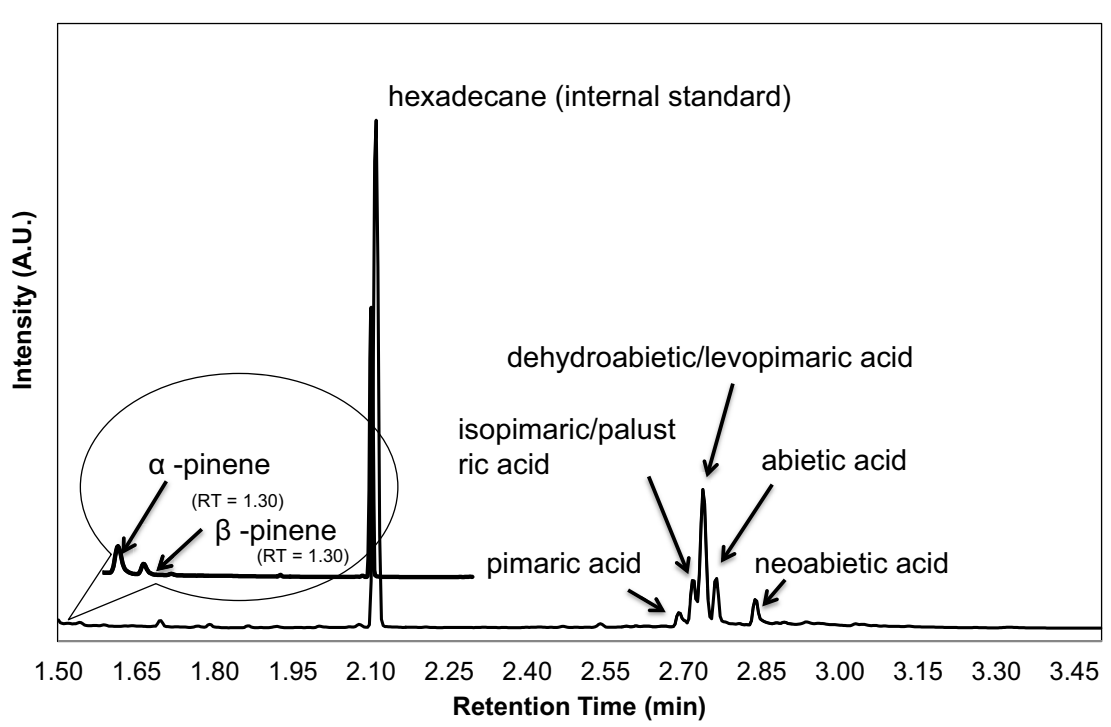

FIGURE 4 | A chromatogram obtained from an underivatized extract from a greenhouse-grown loblolly pine sapling cross section (below 2.05 min) shows mono- and sesquiterpenes. BSTFA derivatized loblolly extract, the chromatogram beyond $2.05 \mathrm{~min}$, is obtained to measure the resin acid diterpenoid content.

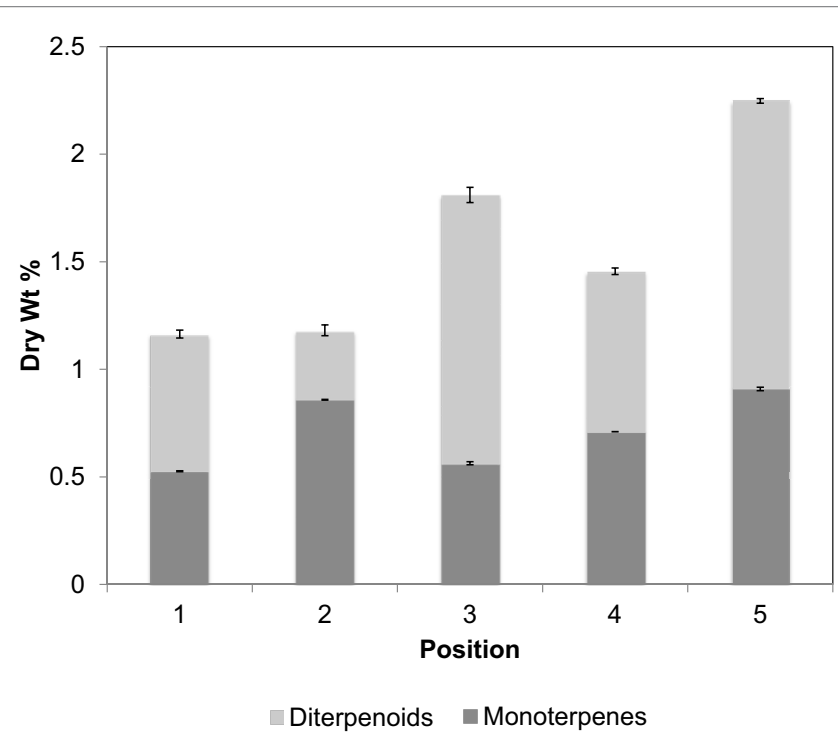

FIGURE 5 | Terpenoid content by dry wt\%, separated into mono- and diterpenoids, for different cross sections of a fresh-cut, greenhousegrown, loblolly pine sapling. Position 1 corresponds to the bottom of the sapling trimmed $1 \mathrm{~cm}$ above the base of the soil and each consecutive number is separated by 2 ", where position 5 is the top cross section of the sapling, approximately 10 in above the soil. Error bars are for duplicate analysis by fast-GC. 4 .

calibrated sesquiterpenes were found to be present in the PS. Both the mono- and diterpenoid content of the cross sections varied along the length of the sapling where the top of the plant (position 5) contained more terpenoids than the lower (position 1) and middle sections (positions 2-4). Dehydroabietic/levopimaric acids were the most abundant diterpenoids present in the sapling, being $0.02-0.6$ dry wt $\%$ of the cross section samples. Abietic acid was also present in high abundance, being $0.1-0.6$ dry wt $\%$ of the sapling samples. Neoabietic acid and isopimaric/palustric acids were present in lower abundances, being around $0.02-0.2$ wt $\%$, and pimaric acid was the lowest, being 0-0.05 dry wt\%. Py-MBMS analysis of cross sections before and after extractions showed the $1 \mathrm{~h}$ room temperature hexane/acetone extractions to be $87.5 \pm 3.6 \%$ efficient (the average from five extracted cross sections based on all diterpenoid ion intensities monitored). The SD of each sapling cross section analyzed (reported in Table 1) reflects the reproducibility of the GC analysis. As a single cross section is unique in terpenoid content, it was not possible to extrapolate the reproducibility of the method by comparing terpenoid content from different cross sections. Hence, method reproducibility is inferred from the PLW experiments and is $<5 \%$ for a homogeneous sample.

\section{DISCUSSION}

A variety of solvent systems were used to extract terpenoids from milled PLW and greenhouse-grown loblolly pine sapling cross sections. Different extraction times and temperatures were tested in order to determine the optimal conditions for extracting the maximum amount of total terpenoids from pine wood samples. Py-MBMS analysis of the biomass samples before and after extraction indicated that the single step extraction using hexane/acetone extractions were efficient at extracting the maximum amount of terpenoid components and that the extractions should be performed over $1 \mathrm{~h}$ at $22^{\circ} \mathrm{C}$. The extraction solvents from the ground PLW and pine sapling cross sections were analyzed by fast-GC/FID, allowing for rapid analysis of the extracted samples to determine their terpenoid content (based on 
dry wt\%). Ground PLW contained more than $20 \mathrm{wt} \%$ terpenoids, whereas, the pine sapling cross sections had varying terpenoid content along the length of the sapling, ranging from 1 to $2.3 \%$ dry wt total terpenoids. Model compound spiking studies using two types of resin acids indicated the preparation of the samples allowed for complete recovery of the terpenoids into the extract solvent and derivatization of extruded pine resin showed that $97 \%$ of terpenoid content could be accounted for using the suggested calibration standards and the suggested GC method. In order to accurately quantify all diterpenoids present, it is essential that all water be removed from the aqueous fraction and freshly activated molecular sieves be used to dry the organic layer. It was found that the average ratio of monoterpenes to diterpenoids in fresh samples should fall within the range of approximately $0.2-0.6$ for fresh samples as anything outside of this indicates that there could be inefficient extraction, monoterpene loss, or lack of derivatization of the diterpenoid. This issue was amplified with the fresh wood and it is possible that water in the biomass could be complicating the analysis.

This method utilizes a single extraction step using a mixture of a polar and non-polar solvent to extract all types of terpenoids at once and does not require the use of specialized equipment, such as a shaker table or Soxhlet apparatus. The method also does not need the samples to be ground as cross sections of saplings could be extracted efficiently. The preparation and analysis of 200 pine samples/week (counting duplicate analysis of both monoterpene and diterpenoid aliquoted extracts, or 800 injections/week) is possible using this method coupled with fast-GC

\section{REFERENCES}

Achotegui-Castells, A., Llusià, J., Hódar, J., and Peñuelas, J. (2013). Needle terpene concentrations and emissions of two coexisting subspecies of Scots pine attacked by the pine processionary moth (Thaumetopoea pityocampa). Acta Physiol. Plant 35, 3047-3058. doi:10.1007/s11738-013-1337-3

Beglinger, E. (1958). Distillation of Resinous Wood. Madison, WI: USDA Forest Service, 496.

Bohlmann, J., and Keeling, C. I. (2008). Terpenoid biomaterials. Plant J. 54, 656-669. doi:10.1111/j.1365-313X.2008.03449.x

Bojovic, S., Jurc, M., Drazic, D., Pavlovic, P., Mitrovic, M., Djurdjevic, L., et al. (2005). Origin identification of Pinus nigra populations in southwestern Europe using terpene composition variations. Trees 19, 531-538. doi:10.1007/ s00468-005-0411-x

Evans, R. J., and Milne, T. A. (1987). Molecular characterization of the pyrolysis of biomass. Energy Fuels 1, 123-137. doi:10.1021/ef00002a001

Firor, R. L. (2011). Analysis of Natural Oils and Extracts Using the Low Thermal Mass LTM Series II System. Wilmington, DE: Agilent Technologies.

Fojtová, J., Lojková, L., and Kubáň, V. (2008). GC/MS of terpenes in walnut-tree leaves after accelerated solvent extraction. J. Sep. Sci. 31, 162-168. doi:10.1002/ jssc. 200700371

Harvey, B. G., Wright, M. E., and Quintana, R. L. (2009). High-density renewable fuels based on the selective dimerization of pinenes. Energy Fuels 24, 267-273. doi:10.1021/ef900799c

Hellier, P., Al-Haj, L., Talibi, M., Purton, S., and Ladommatos, N. (2013). Combustion and emissions characterization of terpenes with a view to their biological production in cyanobacteria. Fuel 111, 670-688. doi:10.1016/j. fuel.2013.04.042

Keeling, C. I., and Bohlmann, J. (2006). Diterpene resin acids in conifers. Phytochemistry 67, 2415-2423. doi:10.1016/j.phytochem.2006.08.019

Lewinsohn, E., Savage, T. J., Gijzen, M., and Croteau, R. (1993). Simultaneous analysis of monoterpenes and diterpenoids of conifer oleoresin. Phytochem. Anal. 4, 220-225. doi:10.1002/pca.2800040506 analysis. Overall, this method is capable of rapidly determining terpenoid content in pine biomass samples, while minimizing solvent extraction steps, equipment usage, sample preparation and handling and increasing GC analysis throughput.

\section{AUTHOR CONTRIBUTIONS}

$\mathrm{AH}-\mathrm{W}$ is a postdoctoral researcher. She performed the extraction experiments, method development, GC analysis, wrote, and edited the manuscript. RS is a PI on the project and did py-MBMS analysis and helped with method development. GP and MD are PIs on the project and helped write/review/edit the manuscript. GP provided biomass samples, as well as method development, sampling and extraction insight, and guidance.

\section{ACKNOWLEDGMENTS}

The authors would like to acknowledge Dr. Gabriella Papa and Dr. James Kirby at the University of California, Berkeley, for purified bisabolene and collaborations with this project.

\section{FUNDING}

This work was supported by the U.S. Department of Energy (DOE) Advanced Research Projects Agency - Energy (ARPA-E) under award No. DE-AR0000209. This work was also supported by the U.S. Department of Energy under Contract No. DE-AC3608-GO28308 with the National Renewable Energy Laboratory.

Luan, W., and Szelewski, M. (2008). Ultra-Fast Total Petroleum Hydrocarbons (TPH) Analysis with Agilent Low Thermal Mass (LTM) GC and Simultaneous Dual-Tower Injection. Wilmington, DE: Agilent Technologies.

Manninen, A.-M., Tarhanen, S., Vuorinen, M., and Kainulainen, P. (2002). Comparing the variation of needle and wood terpenoids in Scots pine provinces. J. Chem. Ecol. 28, 211-227. doi:10.1023/A:1013579222600

Martin, D., Tholl, D., Gershenzon, J., and Bohlmann, J. (2002). Methyl jasmonate induces traumatic resin ducts, terpenoid resin biosynthesis, and terpenoid accumulation in developing xylem of Norway spruce stems. Plant Physiol. 129, 1003-1018. doi:10.1104/pp.011001

Meylemans, H. A., Quintana, R. L., and Harvey, B. G. (2012). Efficient conversion of pure and mixed terpene feedstocks to high density fuels. Fuel 97, 560-568. doi:10.1016/j.fuel.2012.01.062

Monteiro, J., and Veloso, C. (2004). Catalytic conversion of terpenes into fine chemicals. Top. Catal. 27, 169-180. doi:10.1023/B:TOCA.0000013551.99872.8d

Nerg, A., Kainulainen, P., Vuorinen, M., Hanso, M., Holopainen, J. K., and Kurkela, T. (1994). Seasonal and geographical variation of terpenes, resin acids and total phenolics in nursery grown seedlings of Scots pine (Pinus sylvestris L.). New Phytol. 128, 703-713. doi:10.1111/j.1469-8137.1994.tb04034.x

Ormeño, E., Fernandez, C., and Mévy, J.-P. (2007). Plant coexistence alters terpene emission and content of Mediterranean species. Phytochemistry 68, 840-852. doi:10.1016/j.phytochem.2006.11.033

Ormeño, E., Gentner, D. R., Fares, S., Karlik, J., Park, J. H., and Goldstein, A. H. (2010). Sesquiterpenoid emissions from agricultural crops: correlations to monoterpenoid emissions and leaf terpene content. Environ. Sci. Technol. 44, 3758-3764. doi:10.1021/es903674m

Palmer, R. C. (1943). Solvents from pine. Ind. Eng. Chem. 35, 1023-1025. doi:10.1021/ie50406a003

Peralta-Yahya, P. P., Ouellet, M., Chan, R., Mukhopadhyay, A., Keasling, J. D., and Lee, T. S. (2011). Identification and microbial production of a terpene-based advanced biofuel. Nat. Commun. 2, 1-8. doi:10.1038/ncomms1494

Renninger, N. S., Ryder, J. A., and Fisher, K. J. (2011). Jet Fuel Compositions and Methods of Making and Using Same. Emeryville, CA: Google Patents. 
Rodrigues-Corrêa, K. C. D. S., de Lima, J. C., and Fett-Neto, A. G. (2012). Pine oleoresin: tapping green chemicals, biofuels, food protection, and carbon sequestration from multipurpose trees. Food Energy Secur. 1, 81-93. doi:10.1002/fes3.13

Schmidt, A., Nagel, R., Krekling, T., Christiansen, E., Gershenzon, J., and Krokene, P. (2011). Induction of isoprenyl diphosphate synthases, plant hormones and defense signalling genese correlates with traumatic resin duct formation in Norway spruce (Picea abies). Plant Mol. Biol. 77, 577-590. doi:10.1007/ s11103-011-9832-7

Susaeta, A., Peter, G. F., Hodges, A. W., and Carter, D. R. (2014). Oleoresin tapping of planted slash pine (Pinus elliottii Engelm. var. elliottii) adds value and management flexibility to landowners in the southern United States. Biomass Bioenergy 68, 55-61. doi:10.1016/j.biombioe.2014.06.003

Sykes, R., Yung, M., Novaes, E., Kirst, M., Peter, G., and Davis, M. (2009). "Highthroughput screening of plant cell-wall composition using pyrolysis molecular beam mass spectroscopy," in Biofuels, ed. Mielenz J. R. (Golden, CO: Humana Press), 169-183.

Thompson, A., Cooper, J., and Ingram, L. L. Jr. (2006). Distribution of terpenes in heartwood and sapwood of loblolly pine. For. Prod. J. 56, 46-48.

Vallinayagam, R., Vedharaj, S., Yang, W. M., Lee, P. S., Chua, K. J. E., and Chou, S. K. (2014). Pine oil-biodiesel blends: a double biofuel strategy to completely eliminate the use of diesel in a diesel engine. Appl. Energy 130, 466-473. doi:10.1016/j.apenergy.2013.11.025

Varming, C., Andersen, M. L., and Poll, L. (2006). Volatile monoterpenes in black currant (Ribes nigrum L.) juice: effects of heating and enzymatic treatment by $\beta$-glucosidase. J. Agric. Food Chem. 54, 2298-2302. doi:10.1021/jf051938k

Zhao, T., Krokene, P., Björklund, N., Långström, B., Solheim, H., Christiansen, E., et al. (2010). The influence of Ceratocystis polonica inoculation and methyl jasmonate application on terpene chemistry of Norway spruce, Picea abies. Phytochemistry 71, 1332-1341. doi:10.1016/j.phytochem.2010.05.017

Conflict of Interest Statement: The authors declare that the research was conducted in the absence of any commercial or financial relationships that could be construed as a potential conflict of interest.

Copyright (c) 2016 Harman-Ware, Sykes, Peter and Davis. This is an open-access article distributed under the terms of the Creative Commons Attribution License (CC $B Y)$. The use, distribution or reproduction in other forums is permitted, provided the original author(s) or licensor are credited and that the original publication in this journal is cited, in accordance with accepted academic practice. No use, distribution or reproduction is permitted which does not comply with these terms. 